\title{
Vascular Endothelial Growth Factor (VEGF) and Its Controversies about Nephrotic Syndrome and Diabetic Nephropathy: A Systematic Review
}

\section{Seyyed Amir Yasin Ahmadi ${ }^{1}$, Pary Sadat Ahmadi ${ }^{2}$, M ajid Tavafi ${ }^{3}$, Afshin hasanvand $* 1$.}

${ }^{* 1}$ Student Research Committee, Lorestan University of M edical Sciences, Khorramabad, Iran.

${ }^{2}$ General Practitioner, Iran University of M edical Sciences, Tehran, Iran.

${ }^{3}$ Department of Anatomy, Lorestan University of M edical Sciences, Khorramabad, Iran.

\section{ABSTRACT}

\begin{abstract}
Variety of immune factors such as interleukins are involved with nephrotic syndrome. Circulating permeability factors also might be effective. But among them there is a controversy about the vascular endothelial growth factor (VEGF) that seems to have paradoxical effects on diabetic nephropathy and nephrotic syndrome. We want to announce that we have significant increasing of VEGF rate in diabetic nephropathy and in nephrotic syndrome we have increasing in VEGF rate but not significant. Our hypothesis is that this increasing of VEGF is not the reason of nephrotic syndrome; rather, it might be a compensatory regulation to repair endothelial injury.

KEY WORDS: Nephrotic Syndrome, Diabetic Nephropathy, VEGF.
\end{abstract}

Address for correspondence: Afshin Hasanvand, Student Research Committee, Lorestan University of M edical Sciences, Khorramabad, Iran. E-M ail: afshinhasanvand@yahoo.com

\begin{tabular}{|c|c|}
\hline \multicolumn{2}{|r|}{ Online Access and Article Informtaion } \\
\hline 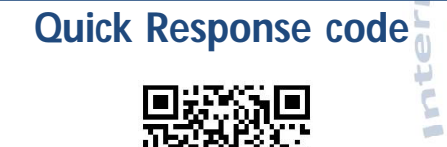 & $\begin{array}{c}\text { International Journal of Integrative Medical Sciences } \\
\text { www.imedsciences.com }\end{array}$ \\
\hline Dol: 10.16965 ijims.2016.106 & 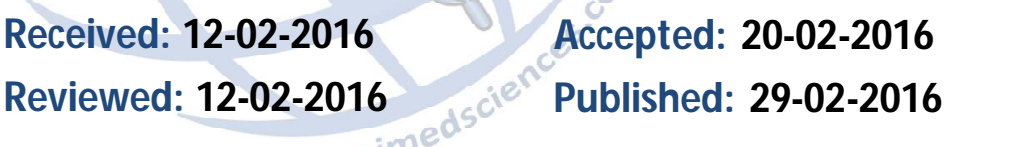 \\
\hline
\end{tabular}

\section{BACKGROUND}

Variety of immune factors such as interleukins are involved with nephrotic syndrome [1]. Circulating permeability factors also might be effective, because such factors seems apoptosis inducer for podocytes- cells that play the key physical role in glomerular filtration barrier [2]. Such factors are mainly synthesized and secreted by $T$ cells existing in blood and regional capillaries [3,4]. Hence previous researches have shown that immunosuppressive treatments could be effective on nephrotic syndrome [1]. As well, numerous of the other factors are involved with glomerular injuries and end-stage conditions [5]. For instance hyperglycemia secondary to diabetes mellitus in both developed and developing countries is one of the main reasons of renal injury end-stage $[6,7]$.

Among the factors above, there is a controversy about the vascular endothelial growth factor (VEGF) in diabetic and non-diabetic nephropathies that seems to have paradoxical effects on diabetic nephropathy and nephrotic syndrome. Thus we intend to discuss and solve the controversy.

\section{METHODS}

This systematic review is based on critical scrutinizing of the literatures in scientific data bases like Pubmed and Web of science search engine.

\section{RESULTS AND DISCUSSION}

Circulatory, immunologic and inflammatory agents such as interleukin-6 (IL6) and tumor 
necrosis factor- alpha (TNF-alpha) have a considered effect on increasing permeability of the glomerular membrane [3]. But among them there is a controversy hole VEGF. Disturbance in the level of VEGF can result in glomerular complications involving with pathogenesis of the most of the kidney disease. As afforded by McCarthy et al, increasing of VEGF could be a therapeutic protocol for nephrotic syndrome [8]. Nowadays it's proved that Renin-Angiotensin System (RAS) and cascade of VEGF is related to glomerular kidney disease. In podocytes angiotensin-II in turn lead to synthesize of type4 collagen through transforming growth factorbeta (TGF-beta) signal of VEGF cascade (9). In nephrotic syndrome, mesangial cells of the glomerulus showed increased rate of expression of profibrotic factors, such as thrombospondin, TGF-beta-2 and 3, as well as the represented angiogenesis factor VEGF [10]. Also the other disorders - involving with cytokines and circulating factors - such as preeclampsia are related to glomerular disease; for example, the angiogenic imbalance in preeclampsia seems related to the development of both endothelial and podocyte damage in the glomerular filtration barrier $[11,12]$.

In the word of schachter [1], VEGF is categorized as the other harmful increasing permeability factors like inflammation stimulatory ILs. But it seems that in verse, VEGF with repairing the endothelial layer of glomerular membrane can lead to repair of the injured glomerular membrane secondary to nephrotic syndrome and improve the glomerular barrier. In fact, VEGF potentially has marvelous regulatory effect on vascular permeability in laboratory conditions [13] that in-vitro is synthesized by immune cells and in-vivo by podocytes [14]. The review article of Brenchley, has it that systemic injection of VEGF cannot induce proteinuria in laboratory animals and among the 15 identified polymorphism of VEGF gene, no significant relation was observed between its three widespread polymorphs and nephrotic syndrome [14].

In contrast with observations about the nephrotic syndrome, increase of VEGF seems harmful for diabetic nephropathy. In both types of diabetes mellitus VEGF was up-regulated and its inhibition with anti-VEGF has had positive effects on diabetic nephropathy complications [9]. Whereas, loss of VEGF was related to glomerulosclerosis- a condition seen in nephrotic syndrome [15]. Metabolic abnormalities have been found in the pathogenesis of diabetic nephropathy which trigger the activation of intracellular signaling molecules that result in the dysregulation of cytokines and vascular growth factors, like VEGF and angiopoietins which are involved in the functional and structural regulation of the glomerular filtration barrier $[6,16]$. Also hyperglycemia is VEGF inducer by itself [17].

About the co-relation of VEGF and nephrotic syndrome some researchers like Brenchley [14] and Morita [18] found no significant and the other one like Honxia [19] achieved the significant rate of VEGF increasing. Though mature podocytes are high differentiated and cannot proliferate, but they can respond to growth factors. Initial response of glomerulus to growth factors is per se beneficial and protective due to induce of hypertrophic cell growth; however, uncontrolled growth factor signaling could result in the induction of programed cell death (apoptosis) and podocyte loss [20]. Of course we do not ignore this experience of the researchers that over expression of VEGF (in particular VEGF-A [9]) could result in glomerular disorders [21,22], but we intend to show that such controversies are originated from genetic polymorphisms in various populations. Another solution for this controversy is that there is a variety of VEGFs (from $A$ to $G$ ) and also variety of tyrosine kinase receptors for them [13] (like VEGFR-1 and VEGFR2) that may clinically perform paradoxical functions [9]. Also about VEGF polymorphism and glomerulonephritis Terzi et al found a nonsignificant relation between VEGF-G and glomerulonephritis and then the authors requested further study [23].

\section{CONCLUSION}

At the end of the present review we can announce that we have increasing rate of VEGF in diabetic nephropathy [17], but about nephrotic syndrome we have non-significant increasing of VEGF. Our hypothesis is that this low increasing 
of VEGF in nephrotic syndrome is not the reason of expression or amplification of the nephrotic syndrome complications; rather, it might be a compensatory regulation to repair endothelial injury (as well as increasing of the immune cells is not the reason of infectious disease).

\section{ABBREVIATION}

VEGF - Vascular Endothelial Growth Factor

TNF - Tumor Necrosis Factor

TGF - Transforming Growth Factor

RAS - Renin Angiotensin System

\section{REFERENCES}

[1]. Schachter AD. The pediatric nephrotic syndrome spectrum: clinical homogeneity and molecular heterogeneity. Pediatric transplantation. 2004;8(4):344-8.

[2]. Wang HH, M isaki T, Taupin V, Eguchi A, Ghosh P, Farquhar MG. GIV/Girdin Links Vascular Endothelial Growth Factor Signaling to Akt Survival Signaling in Podocytes Independent of Nephrin. J Am Soc Nephrol. 2015;26(2):314-27.

[3]. Davin J-C. The glomerular permeability factors in idiopathic nephrotic syndrome. Pediatric nephrology. 2016;31(2):207-15.

[4]. Kaneko K, Tsuji S, Kimata T, Kitao T, Yamanouchi S, Kato S. Pathogenesis of childhood idiopathic nephrotic syndrome: a paradigm shift from T-cells to podocytes. World Journal of Pediatrics. 2015;11(1):21-8.

[5]. Nasri H, Mubarak M. Extracapillary proliferation in IgA nephropathy; recent findings and new ideas. Journal of nephropathology. 2015;4(1):1.

[6]. Dei Cas A, Gnudi L. VEGF and angiopoietins in diabetic glomerulopathy: How far for a new treatment? M etabolism. 2012;61(12):1666-73.

[7]. Nasri H. On the occasion of the world diabetes day 2013; diabetes education and prevention; a nephrology point of view. J Renal Inj Prev. 2013;2(2):31-2.

[8]. McCarthy ET, Sharma M, Savin VJ. Circulating permeability factors in idiopathic nephrotic syndrome and focal segmental glomerulosclerosis. Clinical Journal of the American Society of Nephrology. 2010;5(11):2115-21.

[9]. Badal SS, Danesh FR. New insights into molecular mechanisms of diabetic kidney disease. American Journal of Kidney Diseases. 2014;63(2):S63-S83.

[10]. Brunskill EW, Potter SS. Pathogenic pathways are activated in each major cell type of the glomerulus in the Cd2ap mutant mouse model of focal segmental glomerulosclerosis. Bmc Nephrol. 2015;16.
[11]. Knieczny A, Ryba M , Wartacz J, Czyewska-Buczynska A, Hruby Z, Witkiewicz W. Podocytes in Urine, a Novel Biomarker of Preeclampsia? Adv Clin Exp Med. 2013;22(2):145-9.

[12]. Turner RJ, Bloemenkamp KWM , Penning M E, Bruijn JA, Baelde HJ. From Glomerular Endothelium to Podocyte Pathobiology in Preeclampsia: a Paradigm Shift. Curr Hypertens Rep. 2015;17(7).

[13]. Advani A. Vascular endothelial growth factor and the kidney: something of the marvellous. Curr Opin Nephrol Hy. 2014;23(1):87-92.

[14]. Brenchley PE. Vascular permeability factors in steroid-sensitive nephrotic syndrome and focal segmental glomerulosclerosis. Nephrology Dialysis Transplantation. 2003;18(suppl 6):vi21vi5.

[15]. Schrijvers BF, Flyvbjerg A, De Vriese AS. The role of vascular endothelial growth factor (VEGF) in renal pathophysiology. Kidney international. 2004;65(6):2003-17.

[16]. Wanic K, Krolewski B, Ju WJ, Placha G, Niewczas MA, Walker W, et al. Transcriptome Analysis of Proximal Tubular Cells (HK-2) Exposed to Urines of Type 1 Diabetes Patients at Risk of Early Progressive Renal Function Decline. Plos One. 2013;8(3).

[17]. Tavafi M. Complexity of diabetic nephropathy pathogenesis and design of investigations. J Renal Inj Prev. 2013;2(2):59-62.

[18]. Morita M, Mii A, Shimizu A, Yasuda F, Shoji J, M asuda Y, et al. Glomerular Endothelial Cell Injury and Focal Segmental Glomerulosclerosis Lesion in Idiopathic Membranous Nephropathy. Plos One. 2015;10(4).

[19]. Hongxia Y. Clinical significance of determination of changes of serum IL-6, TNF-á and VEGF levels after treatment in pediatric patients with nephrotic syndrome. 2007.

[20]. Reiser J, Sever S, Faul C. Signal transduction in podocytes-spotlight on receptor tyrosine kinases. Nat Rev Nephrol. 2014;10(2):104-15.

[21]. Veron D, Aggarwal PK, Velazquez H, Kashgarian M, M oeckel G, Tufro A. Podocyte-Specific VEGF-A Gain of Function Induces Nodular Glomerulosclerosis in eNOS Null Mice. J Am Soc Nephrol. 2014;25(8):1814-24.

[22]. Veron D, Reidy KJ, Bertuccio C, Teichman J, Villegas G, Jimenez J, et al. Overexpression of VEGF-A in podocytes of adult mice causes glomerular disease. Kidney international. 2010;77(11):989-99.

[23]. Terzi H, Kayatas M, Korkmaz S, Yildiz G, Candan F. The association between therapeutic outcomes and VEGF G-1154A and C-936T gene polymorphisms in patients with glomerulonephritis. Renal Failure. 2014;36(6):904-7.

\footnotetext{
How to cite this article: Seyyed Amir Yasin Ahmadi, Pary Sadat Ahmadi, M ajid Tavafi, Afshin hasanvand. Vascular Endothelial Growth Factor (VEGF) and Its Controversies about Nephrotic Syndrome and Diabetic Nephropathy: A Systematic Review. Int J Intg M ed Sci 2016;3(2):229-231. DoI: 10.16965/ijims.2016.106
} 